\title{
Orthogonal Experiment in Rheocasting-Rolling for Semi-Solid Magnesium Alloy Used by Slope and Mechanical Stirring
}

\author{
Ying Zhang ${ }^{*}, 1$, Qiang $\mathrm{Ma}^{1}$, Shuisheng $\mathrm{Xie}^{2}$, Jinhua $\mathrm{Xu}^{1}$ and Hongmin Guo ${ }^{1}$ \\ ${ }^{I}$ Department of Mechanical and Electronic Nanchang University, 330029, China \\ ${ }^{2}$ State Key Laboratory for Fabrication \& Processing of Non-ferrous Metals, General Research Institute for Non-ferrous \\ Metals, 100088, China
}

\begin{abstract}
The experiment of the rheocasting-rolling for semi-solid magnesium was carried out on the equipment made by ourselves in our laboratory. Semi-solid AZ91D magnesium slurry was prepared by cooling slope and mchanical sirring The evolution of microstructure under different technological parameters were studied. The results show that the technological parameters have great influence on the microstructure of the semi-solid magnesium slurry. The results show that the optimum parameters of slope method were: pouring temperature 630 degrees; angle of slope $60^{\circ}$; length of slope $0.570 \mathrm{~m}$. the optimum parameters of slope method were: stirring rate $500 \mathrm{r} / \mathrm{min}$; holding time $10 \mathrm{~min}$; stirring time $15 \mathrm{~min}$; casting temperature 560 degrees.
\end{abstract}

Keywords: Magnesium alloy, semi-solid, rheocasting-rolling, microstructure.

\section{INTRODUCTION}

Magnesium alloy have the advantages of light-weight, high intensity ratio, high stiffness/weight ratio, high damping property and electro magnetism shielding property and so on, so recently it has acted an important role in automobile and electric industry as a weight reducing material. But the application of magnesium alloys productions most is diecasting. Die-casting has not been satisfied with the require of production colligation properties, because the thin wall accessories used in the 3C (Computer, Communication, Consumption) products and the high performance magnesium alloy accessories used in the auto products required with the processing techniques higher and higher. Semi-solid metal process (SSM) is a new near net shape technology. And its drip molding is compaction, high mechanical property; little machining, long mould life and can make complex configuration, environment protection, energy conservation, high efficiency. So, it has very vast development foreground $[1,2]$.

\section{ORTHOGONAL EXPERIMENT USED BY SLOPE}

Semi-solid AZ91D magnesium slurry could be obtained by slope method, In this process, metallic melts above liquidus was poured into slope. Because the cooling effect of the slope, nucleation of fine grains grow on the slope wall, then wash into a container. Semi-solid slurry is obtained at last. The semi-solid microstructures are greatly influenced by technological parameters and the slope parameters. Researches on the main four parameters: the slope length, slope angle, pouring temperature and standing time were done in this paper $[3,4]$.

\footnotetext{
*Address correspondence to this author at the Department of Mechanical and Electronic Nanchang University, Nanchang,330029, China; Tel: +8613879120781; E-mail: yzhan@ncu.edu.cn
}

Orthogonal Experiment is to get the optimal experimental result with few experiments using the theory of mathematical statics and orthogonality. Representative and typical experimental points were picked among many experimental points and the experiments were scientifically arranged by the "Orthogonal table".

The method of analysis on result of Orthogonal Experiment was as follows:

Visual analysis: Make the visual analysis table for current experimental data according to the orthogonal table.

Factor index: Draw the diagram of current factor index (effect diagram).

Interaction: Choose two factors to analysis their interaction effects, make the interaction table.

Variance analysis: Set the column for the deviation of the data, and choose the needed $\mathrm{F}$ checking critical value table. Calculate the ratio of square of deviance( $\mathrm{S}$ value) and $\mathrm{F}$. Find out the significant index.

Three problems could be solved by Orthogonal Experiments:

(1) Analyze the relationship between the factors and the index, and find how the factors affecting the index.

(2) Analyze the primary factor and secondary factor affecting the index, find out the primary factor in many quotes influencing index, namely taking the main contradiction.

(3) Seek for the combination of the factors for the optimized index. Through the experiments of the rheocasting-rolling for prophase semi-solid magnesium, analyze and get the stirring speed, stirring time, standing time, pouring temperature, length of slope, angle of slope toward the horizontal direction, parameters such as the pouring temperature, standing 
time, angle of slope and length of slope have large influence on the structure of semi-solid magnesium alloy strip, so these four factors were chosen to do the Orthogonal Experiment.

Choose the L9(34) Orthogonal Experiment table, and do the experiment of four factors and three levels. Four factors are: pouring temperature, length of slope, angle of slope, standing time. 3 levels are: pouring temperatures of 630 degrees, 640 degrees and 650 degrees; angle of slope $570 \mathrm{~mm}, 600 \mathrm{~mm}$ and $630 \mathrm{~mm}$; standing time of $5 \mathrm{~min}, 10 \mathrm{~min}$ and $15 \mathrm{~min}$. The index the result investigates is the spherical degree of the metallographic structure (by centesimal grade).

Table 1 is the intuitive table made according to the result of the experiment designed by the L9(34) Orthogonal Experiment table, 9 experiments were done according to Table 1, and 9 metallographic structure pictures of semisolid magnesium are shown in graph 1 , the basic reference for scoring is the spherical degree of the metallographic structure, a better spherical degree gets a higher score; and at the same time the grain size is taken into consideration, smaller size scores higher, score the metallographic structure in Fig. (1) by the centesimal grade, the scores are as follows successively: $40 ; 50 ; 60 ; 70 ; 75 ; 80 ; 75 ; 80 ; 70$. Fill the result in Table $\mathbf{1}$, and calculate out the range.

\section{OPTIMIZATION OF THE PARAMETERS IN SLOPE}

The metallographic structure obtained by the Orthogonal Experiment is shown in Fig. (1), a large part of the structure in the strip rolled out is comparatively ideal semi-solid structure, crystallized solid particles distributed uniformly around the matrix. The rolling force has played an important role, it means that the strong rolling promotes the structures turning into semi-solid. Because the rolling process is accompanied by the crystallization and solidification of the liquid, the semi-solid has good rheological property, on one side, the friction effects by relative flow makes the solid particles round, on the other side, the rolling force crushes the big solid particles, and combined the small solid particles into big round one.

According to the range analysis by the experimental data:

Range of the factor pouring temperature was 25.000;

Factor of angle took the second place, was 8.333;

Range of slope length was nearly the same as angle of slope, was 8.334;

Range of standing time was the smallest, was 6.667;

It could be concluded that the important order of the factors according to the infection to the index is:

primarily $\rightarrow$ secondly.

pouring temperature $\rightarrow$ angle of slope $\rightarrow$ length of slope $\rightarrow$ standing time.

\section{ORTHOGONAL EXPERIMENT USED BY MECHANICAL STIRRING}

Semi-solid AZ91D magnesium slurry also could be obtained by mechanical stirring method. The principle of this method is that dendritic crystal was broken and eliminated by external mechanical forces. This process can also cause strong convection which make the distribution of ingredients and temperature in liquid more uniform, so constitutional undercooling and thermal undercooling will be decreased, growth of dendritic crystal will be inhibited.

During the process of rheocasting-rolling for semi-solid magnesium alloy used by mechanical stirring, many factors affect on quality and forming of magnesium alloy strip, and the mechanism is very complicated. If all of factors were studied in experiment, the cost of research was very high. In this case, the main influencing factors must be determined. Through analysis, stirring speed, stirring time, standing time and Pouring temperature were the decision parameters for the experimental study. In this paper, the impact of parameters on the process was analyzed by orthogonal experiment.

Table 1. Intuitive Factors of Experimental Analysis Used by Slope

\begin{tabular}{|c|c|c|c|c|c|c|}
\hline Factors & Pouring Temperature & Angle of Slope & Length of Slope & Standing Time [min] & Experiment Result & Remarks \\
\hline experiment1 & $620^{\circ} \mathrm{C}$ & $30^{\circ}$ & $570 \mathrm{~mm}$ & $5 \mathrm{~min}$ & 40 & Fig 1 (a) \\
\hline experiment2 & $620^{\circ} \mathrm{C}$ & $45^{\circ}$ & $600 \mathrm{~mm}$ & $10 \mathrm{~min}$ & 50 & Fig 1 (b) \\
\hline experiment3 & $620^{\circ} \mathrm{C}$ & $60^{\circ}$ & $630 \mathrm{~mm}$ & $15 \mathrm{~min}$ & 60 & Fig 1 (c) \\
\hline experiment4 & $630^{\circ} \mathrm{C}$ & $30^{\circ}$ & $600 \mathrm{~mm}$ & $15 \mathrm{~min}$ & 70 & Fig $1(d)$ \\
\hline experiment5 & $630^{\circ} \mathrm{C}$ & $45^{\circ}$ & $630 \mathrm{~mm}$ & $5 \mathrm{~min}$ & 75 & Fig 1 (e) \\
\hline experiment6 & $630^{\circ} \mathrm{C}$ & $60^{\circ}$ & $570 \mathrm{~mm}$ & $10 \mathrm{~min}$ & 80 & Fig 1 (f) \\
\hline experiment7 & $640^{\circ} \mathrm{C}$ & $30^{\circ}$ & $630 \mathrm{~mm}$ & $10 \mathrm{~min}$ & 75 & Fig $1(\mathrm{~g})$ \\
\hline experiment8 & $640^{\circ} \mathrm{C}$ & $45^{\circ}$ & $570 \mathrm{~mm}$ & $15 \mathrm{~min}$ & 80 & Fig $1(h)$ \\
\hline experiment9 & $640^{\circ} \mathrm{C}$ & $60^{\circ}$ & $600 \mathrm{~mm}$ & $5 \mathrm{~min}$ & 70 & Fig 1 (i) \\
\hline Mean value 1 & 50.000 & 61.667 & 65.000 & 63.333 & & \\
\hline Mean value 2 & 75.000 & 70.000 & 63.333 & 66.667 & & \\
\hline Mean value 3 & 75.000 & 68.333 & 71.667 & 70.000 & & \\
\hline range & 25.000 & 8.333 & 8.334 & 6.667 & & \\
\hline
\end{tabular}



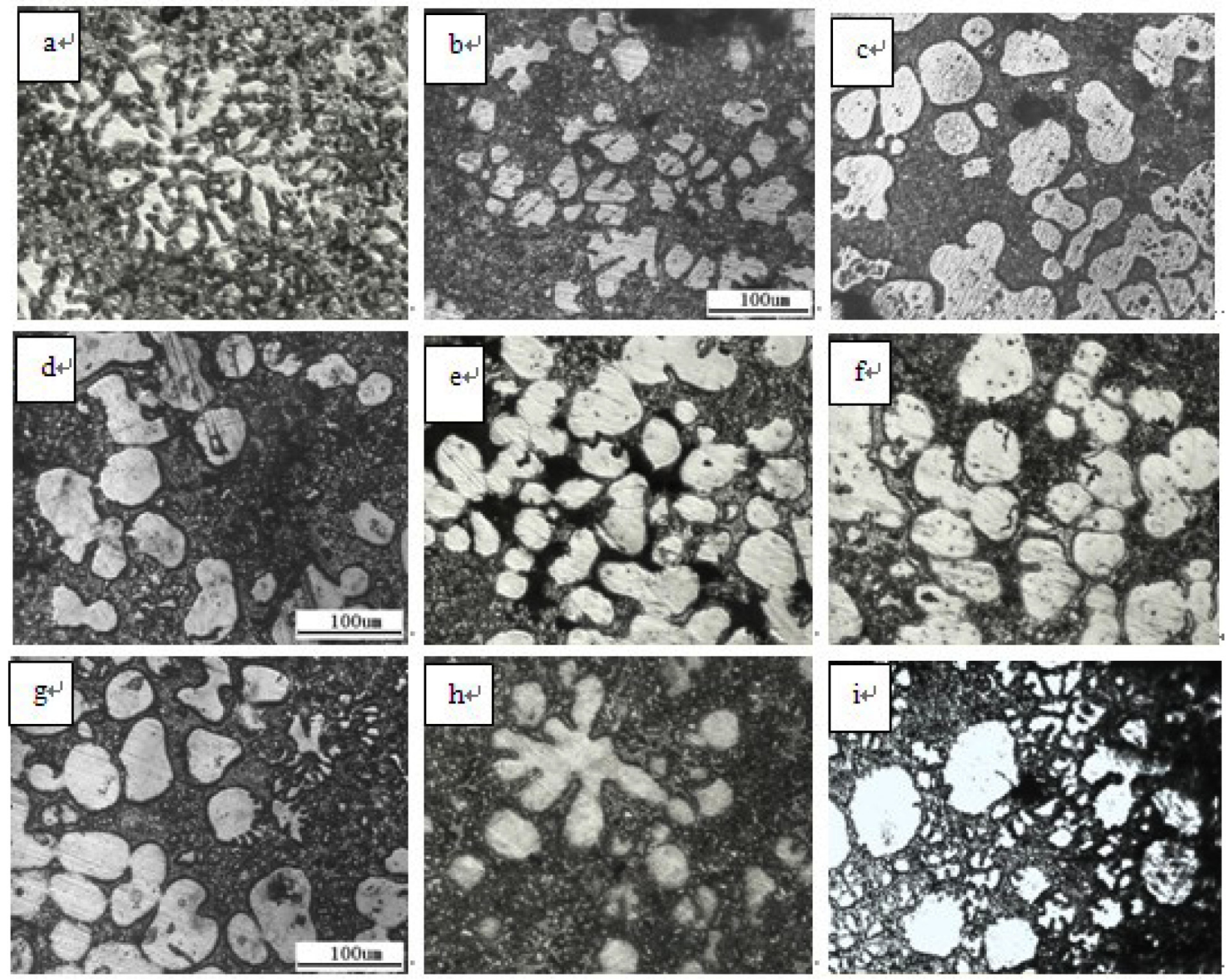

Fig. (1). The metallographic structure of semi-solid magnesium obtained by rheocasting-rolling in the Orthogonal Experiment for slope method.

The L9(34) Orthogonal Experiment table was Chosen, and experiments of four factors and three levels were done, the experimental plan was shown in Table 2. The quality indicators of the semi-solid slurry includes: solid rate, appearance of the primary phase, uniformity of the grain, mean value and uniformity of the grain size. In general, the rounder primary $\alpha$ phase, finer grain, more uniform grain size and distribution, means that the semi-solid metal slurry quality is better. The indicators investigated was the microstructure roundness of the semi-solid AZ91D magnesium alloy (the hundred-mark system).

Nine groups of experiment were carried out under the parameters listed in Table 2, as shown by Fig. (3), nine groups of semi-solid metallographic structure were obtained, the metallographic structures were used to analyze the effect of each experiment, they will be graded on the roundness of the metallographic structure, a rounder metallographic got a higher score; the grain size will also be taken into consideration, a smaller grain got a higher score.
It can be seen from Fig. (3), considerable parts of the structures in the strips were relatively ideal semi-solid structure, the primary spherical solid particles distributed uniformly in the matrix, the rolling force has played a important role. That means the strong rolling promoted the growth of semi-solid structure. Because the solidification process was accompanied by rheocasting-rollinig, semi-solid slurry have good rheological properties during the rolling, on one hand, friction in the relative movement between the solid and liquid make the solid particles rounder, on the other hand, the rolling force broke the big solid particles and combined the small ones together, making the grains uniform.

Intuitive analysis table of the Orthogonal Experiment obtained by the calculation and analysis of the experimental data was shown in Table 2.

Table 3 was the variance analysis table of the orthogonal experiments, factor variance analysis is a mathematical method to distinguish the difference of the experimental data caused by the factor level or alternation in interaction and the 
Table 2. Intuitive Factors of Experimental Analysis Used by Mechanical Stirring

\begin{tabular}{|c|c|c|c|c|c|c|}
\hline Factors & Stirring Speed & Stirring Time & Standing Time & Pouring Temperature & Experiment Result & Remarks \\
\hline Experiment1 & $100 \mathrm{r} / \mathrm{min}$ & $5 \mathrm{~min}$ & $5 \mathrm{~min}$ & $550^{\circ} \mathrm{C}$ & 40 & Fig. 2 (1) \\
\hline Experiment2 & $100 \mathrm{r} / \mathrm{min}$ & $10 \mathrm{~min}$ & $10 \mathrm{~min}$ & $560^{\circ} \mathrm{C}$ & 50 & Fig. $2(2)$ \\
\hline Experiment3 & $100 \mathrm{r} / \mathrm{min}$ & $15 \mathrm{~min}$ & $15 \mathrm{~min}$ & $570^{\circ} \mathrm{C}$ & 60 & Fig. 2 (3) \\
\hline Experiment 4 & $500 \mathrm{r} / \mathrm{min}$ & $5 \mathrm{~min}$ & $10 \mathrm{~min}$ & $570^{\circ} \mathrm{C}$ & 75 & Fig. 2 (4) \\
\hline Experiment5 & $500 \mathrm{r} / \mathrm{min}$ & $10 \mathrm{~min}$ & $15 \mathrm{~min}$ & $550^{\circ} \mathrm{C}$ & 80 & Fig. 2 (5) \\
\hline Experiment6 & $500 \mathrm{r} / \mathrm{min}$ & $15 \mathrm{~min}$ & $5 \mathrm{~min}$ & $560^{\circ} \mathrm{C}$ & 75 & Fig. 2 (6) \\
\hline Experiment7 & $1000 \mathrm{r} / \mathrm{min}$ & $5 \mathrm{~min}$ & $15 \mathrm{~min}$ & $560^{\circ} \mathrm{C}$ & 75 & Fig. 2 (7) \\
\hline Experiment8 & $1000 \mathrm{r} / \mathrm{min}$ & $10 \mathrm{~min}$ & $5 \mathrm{~min}$ & $570^{\circ} \mathrm{C}$ & 80 & Fig. 2 (8) \\
\hline Experiment9 & $1000 \mathrm{r} / \mathrm{min}$ & $15 \mathrm{~min}$ & $10 \mathrm{~min}$ & $550^{\circ} \mathrm{C}$ & 60 & Fig. 2 (9) \\
\hline Mean value 1 & 50.000 & 63.333 & 65.000 & 60.000 & & \\
\hline Mean value 2 & 76.667 & 70.000 & 61.667 & 66.667 & & \\
\hline Mean value 3 & 71.667 & 65.000 & 71.667 & 71.667 & & \\
\hline Range & 26.667 & 6.667 & 10.000 & 11.667 & & \\
\hline
\end{tabular}

error, the variance ratio was indicated by $\mathrm{F}, \mathrm{F}=1$ means that the changes in the level of factors have the equal influence on the results; $\mathrm{F}<1$ means that changes in the level of factors have little influence; $\mathrm{F}>1$ means that errors and changes in factors level have a significant influence. In the intuitive analysis method, the level of influence can be determined by the range of the factors to the indicators, the influence is greater when the range is larger, and slighter when the range is smaller.

The interaction between pouring temperature and standing time was shown in Table 4; Interaction between stirring time and stirring rate was shown in Table 5; Effecting curve for the orthogonal experiments of semi-solid AZ91D magnesium alloy rheocasting-rolling was shown in Fig. (4).

It could be seen from Table 2: the range of the stirring speed was maximum, up to 26.667 , the range of the stirring time was minimum, which was 6.667 , range of the standing time was 10.000 , range of pouring temperature was 11.667. Therefore, the influencing factors can be arranged in decreasing sequence as follows: stirring speed $\rightarrow$ standing time $\rightarrow$ pouring temperature $\rightarrow$ stirring time.

It can be seen in Table 3 that the sum of square of deviations of the stirring rate was the maximum, the sum of square of deviations of the stirring time was the minimum.

\section{CONCLUSION}

Effect curve of the main experimental parameters could be obtained by orthogonal software, as shown in Figs. $(2,4)$. The wave curve of every parameter could be seen intuitively. It could be concluded :

In the process of Semi-solid slurry obtained by slope:

(1) The pouring temperature should be $630^{\circ} \mathrm{C}$;

(2) The angle of slope toward the horizontal direction should be $60^{\circ}$;

(3) The length of slope should be $0.570 \mathrm{~m}$;

Fig. (2). Experiment effects. 

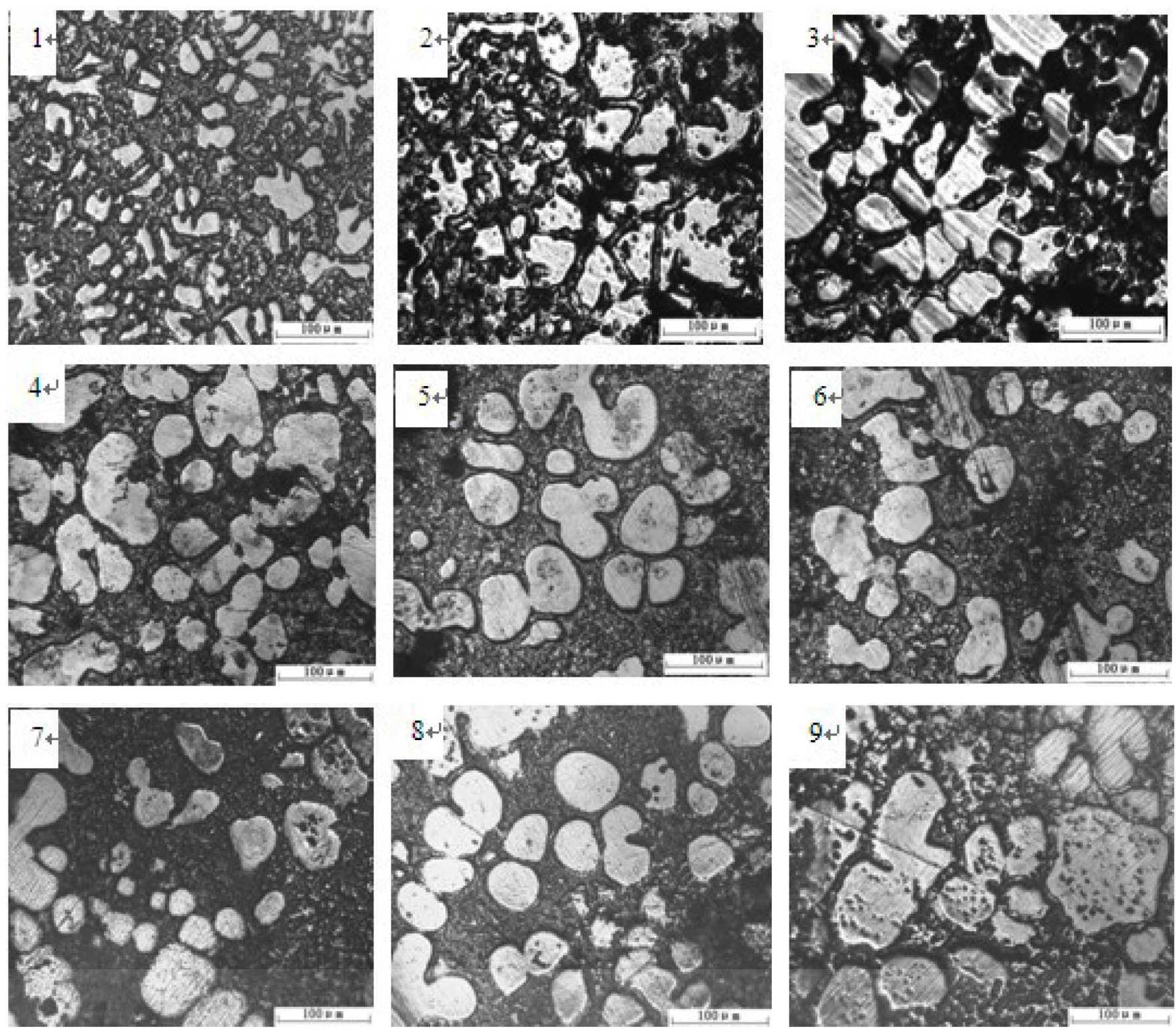

Fig. (3). The metallographic structure of semi-solid magnesium obtained by rheocasting-rolling in the Orthogonal Experiment for mechanical stirring.

Table 3. Variance Analysis Table of the Orthogonal Experiment

\begin{tabular}{|c|c|c|c|c|c|}
\hline Factors & Sum of Square of Deviations & Degree of Freedom & Rate of F & Critical Value of F & Significance \\
\hline \hline Stirring speed & 1205.556 & 2 & 2.942 & 4.460 & Significant \\
\hline Stirring time & 72.222 & 2 & 0.176 & 4.460 & slighter \\
\hline Standing time & 155.556 & 2 & 0.380 & 4.460 & slighter \\
\hline Pouring temperature & 205.556 & 2 & 0.502 & 4.460 & slighter \\
\hline Error & 1638.89 & 8 & & \\
\hline
\end{tabular}

(4) The standing time should be $5 \mathrm{~min}$.

The optimization coefficients obtained by Orthogonal Experiment were: pouring temperature $630{ }^{\circ} \mathrm{C}$; angle of slope $60^{\circ}$; length of slope $0.570 \mathrm{~m}$; standing time $5 \mathrm{~min}$.

In the process of Semi-solid slurry obtained by mechanical stirring:
(1) A higher speed should be used rather than the low speed(such as $100 \mathrm{r} / \mathrm{min}$ ), but there was no big difference between $500 \mathrm{r} / \mathrm{min}$ and $1000 \mathrm{r} / \mathrm{min}$, a higher speed makes the processing technic more complicated, so $500 \mathrm{~m} / \mathrm{min}$ was chosen. 
Table 4. The Interaction Between Pouring Temperature and Standing Time

\begin{tabular}{|c|c|c|c|}
\hline Temperature & $5 \mathrm{~min}$ & $10 \mathrm{~min}$ & $15 \mathrm{~min}$ \\
\hline $550^{\circ} \mathrm{C}$ & 40.000 & 60.000 & 80.000 \\
\hline $560^{\circ} \mathrm{C}$ & 75.000 & 50.000 & 75.000 \\
\hline $570^{\circ} \mathrm{C}$ & 80.000 & 75.000 & 60.000 \\
\hline
\end{tabular}

Table 5. Interaction Between Stirring Time and Stirring Rate

\begin{tabular}{|c|c|c|c|}
\hline Stirring Speed & $\mathbf{1 0 0 r} / \mathbf{m i n}$ & $\mathbf{5 0 0} \mathbf{r} / \mathbf{m i n}$ & $\mathbf{1 0 0 0} \mathbf{r} / \mathbf{m i n}$ \\
\hline \hline $5 \mathrm{~min}$ & & & \\
\hline $10 \mathrm{~min}$ & 40.000 & 75.000 & 75.000 \\
\hline $15 \mathrm{~min}$ & 50.000 & 80.000 & 80.000 \\
\hline
\end{tabular}

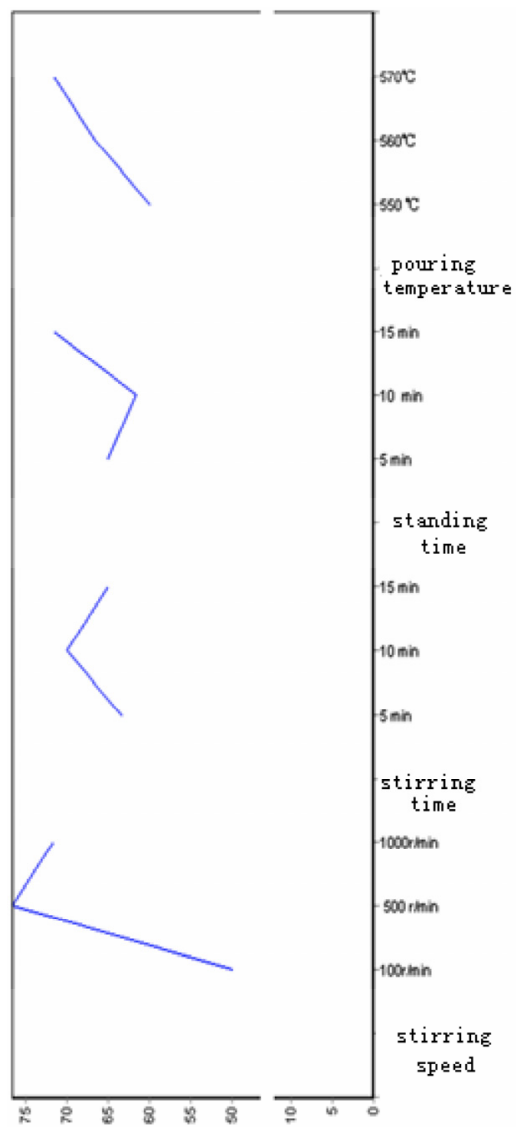

Fig. (4). Effect curve for the orthogonal experiments of semi-solid AZ91D magnesium alloy rheocasting-rolling.
(2) Effect of 15-minutes stirring time is obvious; no big difference was found after 10-minutes holding time, so 10-minutes holding time was chosen.

(3) The casting temperature should be $560^{\circ} \mathrm{C}$

Consequently, the optimized technological parameters obtained by the orthogonal experiments of semi-solid AZ91D magnesium alloy rheocasting-rolling was: stirring rate $500 \mathrm{r} / \mathrm{min}$; holding time $10 \mathrm{~min}$; stirring time $15 \mathrm{~min}$; casting temperature $560^{\circ} \mathrm{C}$.

\section{ACKNOWLEDGEMENTS}

This work is supported by the National Natural Science Foundation of China (NO. 51066005) (NO.50804023).

\section{REFERENCES}

[1] Liang D, Cowley C B. The twin-roll strip casting of magnesium. JOM 2004; 56(5): 26-28.

[2] Xie SS. Development and Application of Semi-solid metal processing technology. Special Casting \& Non-ferrous Alloys (Diecasting monograph) 2007; 20-28.

[3] Watari H, Haga T, Kogac N. Feasibility study of twin roll casting process for magnesium alloys. J Mater Proc Technol 2007; 192193: 300 .

[4] Y. Zhang, M.P. Geng and L. Cheng, et al. Influence of Processing parameters on microstructure of casting rolling semi-solid AZ91D magnesium alloys. Solid State Phenom 2008; 141-143: 535-538.

[5] Ying Z, Shuisheng X, Maopeng G. Investigation in RheoCastingrolling for Semi-solid Magnesium Alloy Used By Slope. Adv Mater Res 2010; 89-91: 681-686. 